\title{
Review Article \\ The Cellulose Nanofibers for Optoelectronic Conversion and Energy Storage
}

\author{
Yongfeng Luo, ${ }^{1}$ Jianxiong Zhang, ${ }^{1} \mathrm{Xi} \mathrm{Li},{ }^{1}$ Chunrong Liao, ${ }^{1}$ and Xianjun $\mathrm{Li}^{2}$ \\ ${ }^{1}$ College of Science, Central South University of Forestry and Technology, Changsha, Hunan 410004, China \\ ${ }^{2}$ Material Science and Engineering School, Central South University of Forestry and Technology, Changsha, Hunan 410004, China \\ Correspondence should be addressed to Xianjun Li; lxjmu@163.com
}

Received 6 May 2014; Accepted 26 June 2014; Published 25 August 2014

Academic Editor: Li Li

Copyright (c) 2014 Yongfeng Luo et al. This is an open access article distributed under the Creative Commons Attribution License, which permits unrestricted use, distribution, and reproduction in any medium, provided the original work is properly cited.

\begin{abstract}
Cellulose widely exists in plant tissues. Due to the large pores between the cellulose units, the regular paper is nontransparent that cannot be used in the optoelectronic devices. But some chemical and physical methods such as 2,2,6,6-tetramethylpiperidine-1oxyl radical (TEMPO) oxidation can be used to improve the pores scale between the cellulose units to reach nanometer level. The cellulose nanofibers (CNFs) have good mechanical strength, flexibility, thermostability, and low thermal expansion. The paper made of these nanofibers represent a kind of novel nanostructured material with ultrahigh transparency, ultrahigh haze, conductivity, biodegradable, reproducible, low pollution, environment friendly and so on. These advantages make the novel nanostructured paper apply in the optoelectronic device possible, such as electronics energy storage devices. This kind of paper is considered most likely to replace traditional materials like plastics and glass, which is attracting widespread attention, and the related research has also been reported. The purpose of this paper is to review CNFs which are applied in optoelectronic conversion and energy storage.
\end{abstract}

\section{Introduction}

Cellulose mainly exists in plant cell walls; the hierarchical structure of the plant cell walls is complicated; fiber in the cell wall is a kind of nature nanostructure cellulose. CNFs are rapidly developed since Turbak found microfibril in 1983. The CNFs preparation and their application in composite materials are widely reported. Nanofibers are defined as nanosized fiber with size of less than $100 \mathrm{~nm}$. Although they are thin, they have high aspect ratio and strong mechanical properties. The three-dimensional (3D) hierarchical structure is demonstrated in Figure 1. CNFs whose surface contains abundance of light base group have a kind of extremely potential reinforced material, which can replace traditional materials such as glass and plastic. Our country is rich in timber resource, which can be used to extract CNFs. CNFs extracted from tree have excellent performance such as renewability, low consumption, low density, biocompatibility, biodegradability, and being environmentally friendly. The characteristics have extremely far-reaching significance to utilize the function and high added-value of CNFs.
In addition to the characteristics described above, CNFs also have some advantages which are abundance of resource, high aspect ratio, and specific surface area. Simultaneously, nanofibers can be interwoven into mesh tangles in polymer structure. These nanofibers maintain strong mechanical strength and flexibility.

As we know, paper is made from cellulose in wood fiber. There is great difference between the traditional paper and the novel nanostructured paper. Under the same deposition conditions, traditional papers consisting of microsized pulp fibers produce very low conductivity lines with nonuniform boundaries because of their larger pore structures. Although they are both composed of lignocellulose, CNFs paper, as low-cost substrate for flexible electronics and energy devices, has gained extensive attention because of its flexibility, thermostability and low thermal expansion, highly ultrahigh transparency and ultrahigh haze, conductivity, biodegradable, reproducible and low pollution environment friendly. The novel paper application in optoelectronic devices is an emerging research area gathering significant attention. Many recent advances in application of nanofiber involve 


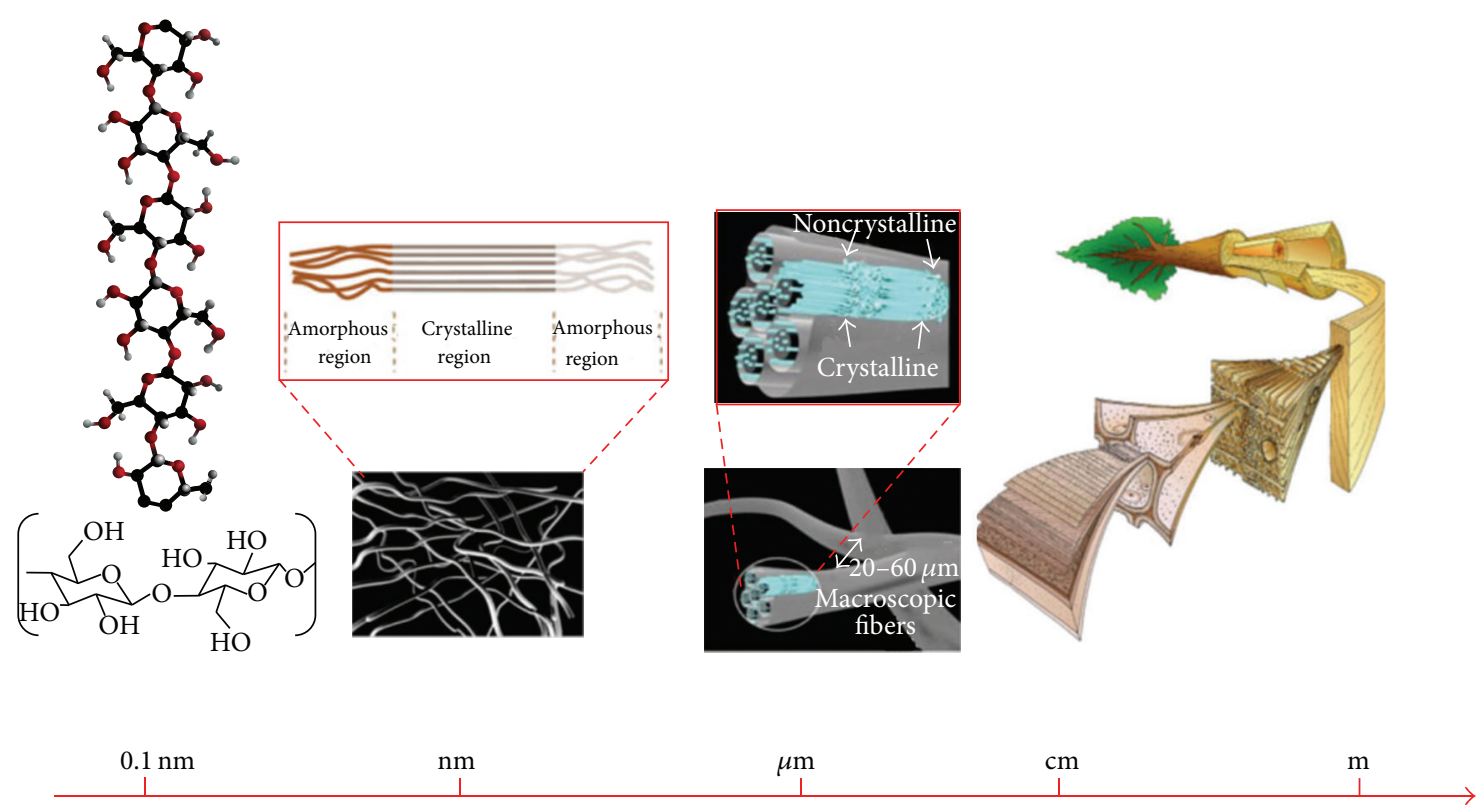

FIGURE 1: The three-dimensional (3D) hierarchical structures show the hierarchical structure of cellulose from the wood cell wall to microfibril to nanofibril to a cellulose molecule [7].

fabricating electronic devices, such as displays, transistors, batteries, sensors, and solar cells [1-4]. Paper electronics is an attractive solution for low-cost applications since it is renewable, scalable, light weight, mechanically flexible, and disposable $[5,6]$.

In this paper we mainly review the preparation methods of CNFs and the properties of the nanostructured paper and expound the special application in energy storage devices.

\section{CNFs}

Cellulose is linear polymers composed of the group Dglucose by $1,4-\beta$-glucoside connection. The fundamental unit of cellulose is cellulose elementary fibril, and 36 cellulose molecules that link together form a cellulose elementary fibril whose length is about $30 \mathrm{~nm}$. Cellulose elementary fibril is composed of cellulose microfiber with diameter of 10$20 \mathrm{~nm}$ and length of several hundred nanometers to a few microns. Microfiber constitutes the fiber which is the primary substance of the tree.

\subsection{Preparation of CNFs}

2.1.1. Chemical Preparation of CNFs. Chemical preparation method of CNFs is the enzyme hydrolysis. The amorphous area of fiber is destroyed to isolate nanocrystallite under the condition of strong acid. Morán et al. [8] treated sisal fiber with $60 \% \mathrm{H}_{2} \mathrm{SO}_{4}$ about 30 minutes extract nanometer crystallite under temperature of $45^{\circ} \mathrm{C}$. Martins et al. [9] found the acid hydrolysis conditions of commodity cotton pulp, which is in $45^{\circ} \mathrm{C}$ with $6.5 \mathrm{M} \mathrm{H}_{2} \mathrm{SO}_{4}$, processing in 75 minutes to get nanometer crystallite length in $150 \pm 50 \mathrm{~nm}$, diameter of $14 \pm 5 \mathrm{~nm}$, and has good thermal stability.
2.1.2. Physical Preparation of CNFs. Mechanical grinding is often used to manufacture cellulose. Nakagaito and Yano [10] found that the pulp ground 16-30 times can completely extract the CNFs. Chakraborty et al. [11] obtained nanofibers by grinding the pulp in $125000 \mathrm{rpm}$.

High intensity ultrasonic treatment is also a kind of effective method of preparation of CNFs. Pretreatment of fibers will be diluted to $0.05 \%$ of suspension, and then using $20-25 \mathrm{kHz}$ ultrasonic treatment for 30 minutes, CNFs with diameter of $30-80 \mathrm{~nm}$ will be obtained. The advantage of physical preparation method is a very simple operation and without impurities, but this method causes large energy consumption and it is easy to form flocculation.

2.1.3. Biological Preparation of CNFs. Cellulose enzymes are often used to prepare CNFs and cellulose enzymes are able to attack the amorphous regions of the fiber so that the fiber structure splits easier. Since, only the enzyme treatment is hard to get CNFs, mechanical treatment must be combined to get qualified CNFs. Janardhnan and Sain [12] found that the enzyme-treated fibers in the high shear grinding can obtain a smaller size microfiber. Pääkkö et al. [13] mechanically dispersed the fibers that have disposed with the enzyme getting spindle-shaped nanofibers.

Bacterial cellulose is another method to prepare nanofibers. Bacterial cellulose is firstly reported by Brown in 1886. Under the appropriate condition, Acetobacter xylinum can secrete cellulose microfibril in diameter of $1.78 \mathrm{~nm}$ by concatenating glucose with D-glycosidic bond to form polydextrose. Due to the effect of hydrogen bonding, bacterial cellulose microfibril will form a fiber ribbon with length and width of 30-100 nm and thickness of 3-8 nm. 
2.1.4. TEMPO-Oxidized CNFs. The chemical and biological method is low yield and difficult to control, so it cannot perfectly prepare CNFs. TEMPO-oxidized CNFs have attracted widespread attention. Individualized CNFs with width of 3$4 \mathrm{~nm}$ and length of at least a few microns from wood were prepared completely by 2,2,6,6-tetrame-thylpiperidine-1-oxyl radical (TEMPO-) mediated oxidation under moderate aqueous conditions [14-16]. The process of TEMPO oxidized CNFs is as follows.

The application of TEMPO catalytic oxidation has opened up a new field of effective and selective conversion chemistry of alcoholic hydroxyl groups to ketones, aldehydes, and carboxyl groups under mild conditions. The related studies have been extensively carried out in recent years [17, 18]. Particularly, deNooy et al. first applied TEMPO-mediated oxidation to water-soluble polysaccharides such as starch, amylodextrin, and pullulan for regioselective conversion of C6 primary hydroxyls to carboxylate groups. Isogai et al. [19] reviewed preparation methods and fundamental characteristics of TEMPO-oxidized CNFs. Catalytic amounts of TEMPO and $\mathrm{NaBr}$ were dissolved in polysaccharide solutions at $\mathrm{pH}$ 10-11, and oxidation was started when $\mathrm{NaClO}$ solution was added as a primary oxidant. The efficient conversion of primary hydroxyl groups to carboxylates via aldehydes is hypothesized to proceed according to the mechanism shown in Figure 2 [20, 21]. All kinds of TEMPO-mediated oxidation reactions of mono-, oligo-, and polysaccharides for conversion of primary hydroxyls to carboxylate groups have been reviewed.

According to the approach shown in Figure 3, the C6 primary hydroxyls of cellulose were oxidized to C6 carboxylate groups by $\mathrm{TEMPO} / \mathrm{NaBr} / \mathrm{NaClO}$ oxidation in water at $\mathrm{pH}$ 10-11. The oxidation process can be indicated from the pattern of aqueous $\mathrm{NaOH}$ consumption, which is continuously added to the reaction mixture to keep the $\mathrm{pH}$ at 10 during the oxidation. When TEMPO/NaBr/NaClO oxidation was applied to native cellulose even for extended reaction times or under harsh oxidation conditions, almost no or only a small number of water-soluble products were obtained [22]. On the other hand, pulp of regenerated and mercerized cellulose and ball-milled and liquid $\mathrm{NH}_{3}$-treated native cellulose became clear solution when the oxidation proceeded; water-soluble oxidized products were obtained in this fashion. The oxidized products had almost coessential chemical structures of sodium (1/4)-b-D-poly-glucuronate or Na salt of cellouronic acid consisting of D-glucuronosyl units alone. So the C6 primary hydroxyls of cellulose can be entirely and selectively converted to $\mathrm{C} 6 \mathrm{Na}$ carboxylate groups by TEMPO-mediated oxidation. It was demonstrated that not only are C6-carboxylate groups formed by the oxidized TEMPO but also $\mathrm{NaBrO}$ and/or $\mathrm{NaClO}$ exist in the TEMPO $/ \mathrm{NaBr} / \mathrm{NaClO}$ system at $\mathrm{pH} 10$ (see Figure 3).

\section{Structures of Cellulose Nanopaper}

The basic structure of CNFs determinates the light transmittance of paper. Wood pulp for paper is primarily comprised of cellulose, and most lignin hemicellulose is removed during the pulping and bleaching procedure. Cellulose is polymerized by a repeating unit of glucose. There are many components of ether, hydroxyl, carbon-carbon, and carbonhydrogen bonds in the cellulose, so it does not adsorb light in the visible wavelength, which renders the pure cellulose colorless.

Traditional paper is made of fibrous network permeated by microsized air cavities, and the different refractive indices of the cellulose and air (1.5 and 1.0, resp.) lead to the light scattering at the fiber surfaces, so traditional paper is opaque. Fang et al. [23] reported that all the fibers are arranged into a random fibrous network with lots of microsized air cavities in a traditional paper substrate (see Figure 4(a)). Due to the fact that the size of the fibers is much larger than the visible wavelength, incident light will largely scatter. This large difference between refractive indexes invokes slight scattering at the fiber surfaces and is revealed as the nontransparent paper. For paper made of bleached softwood kraft fibers, the specific mass attenuation coefficient is $200-350 \mathrm{~cm}^{2} \mathrm{~g}^{-1}$ and the specific light absorption coefficient is $1-10 \mathrm{~cm}^{2} \mathrm{~g}^{-1}$ [24].

In comparison with regular paper, CNFs with diameter of 5-30 nm are used to fill the pores within the paper and, thus, microsized pores that cause light scattering are reduced to nanosize by adding CNFs via a papermaking method. Consequently, minimal light scattering occurs due to the reduced number of open spaces and matched refractive index between the effective index of the transparent paper and air, which allow more light to pass directly through the paper rather than getting scattered (Figure 4(b)) and lead to excellent optical transparency of up to $91.5 \%$ (Figure $4(\mathrm{c})$ ).

\section{Properties of CNFs Paper}

4.1. Mechanical Property. The mechanical properties of paper play an important role for the optoelectronic device. A SEM image of the nanopaper dried after filtration from a water suspension is shown in Figure 5(a). This SEM image shows that the nanofiber cellulose is randomly distributed in flat. Although we observe the nanopaper looks like a thin plastic film with the naked eye, in fact it has a unique porous structure in the nanoscale that makes a difference with traditional transparent substrates. The typical size of pore is $10-50 \mathrm{~nm}$. The fiber porous network structure makes the nanopaper own excellent flexibility. The cross profile (Figure 5(b)) shows that the nanopaper has a layered nanoporous structure. This structure enables the nanopaper to bend the electronics devices based on the effective release of the stress in the active layers generated. Due to the tightly packed nanofibrillar network and numerous fiberfiber hydrogen bonds, the remarkable high tensile strength, Young's modulus, and toughness become other interesting properties of the transparent nanopaper. These properties make the transparent nanopaper ten times stronger, lighter, and more flexible than traditional paper. The typical stressstrain curve for nanopaper with different porosities is shown in Figure 5(c). It demonstrates that the higher porosity has the lowest tensile strength. The nanopaper with $19 \%$ porosity has the highest tensile strength about $205 \mathrm{MPa}$. Combined 


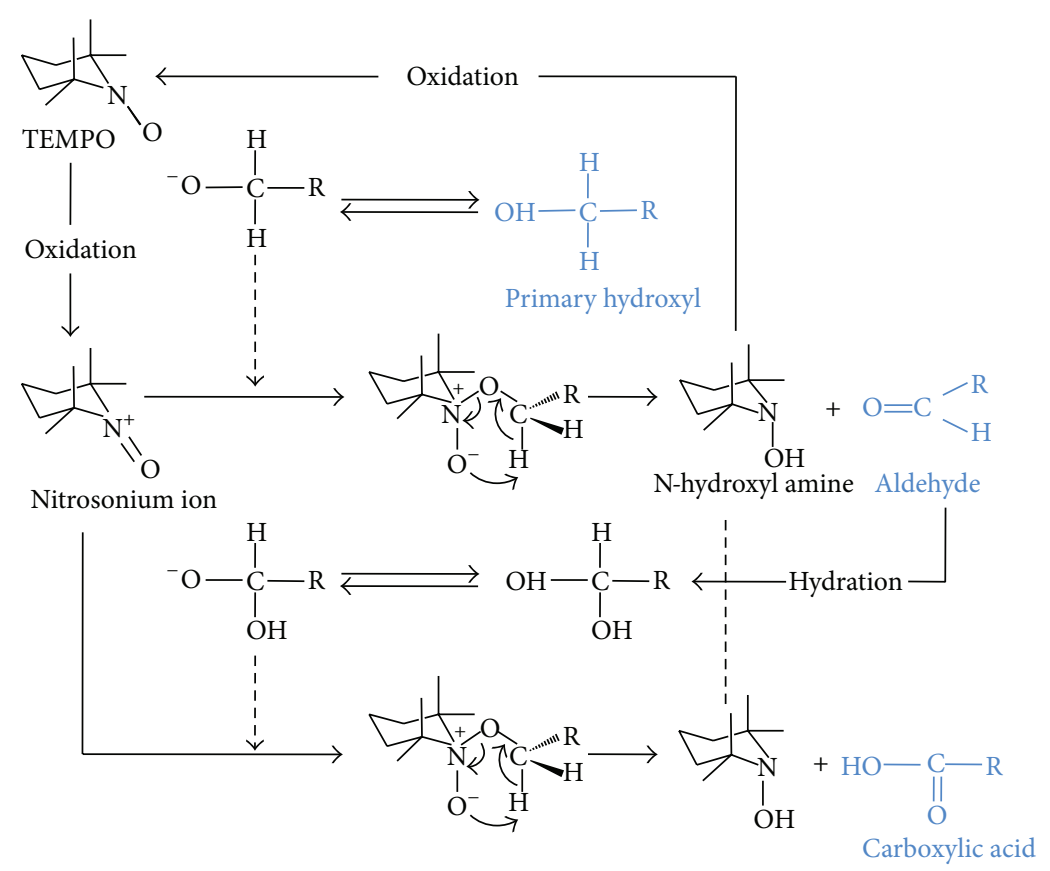

FIGURE 2: TEMPO-mediated oxidation reactions of the efficient conversion of primary hydroxyl groups to carboxylates via aldehydes [19].

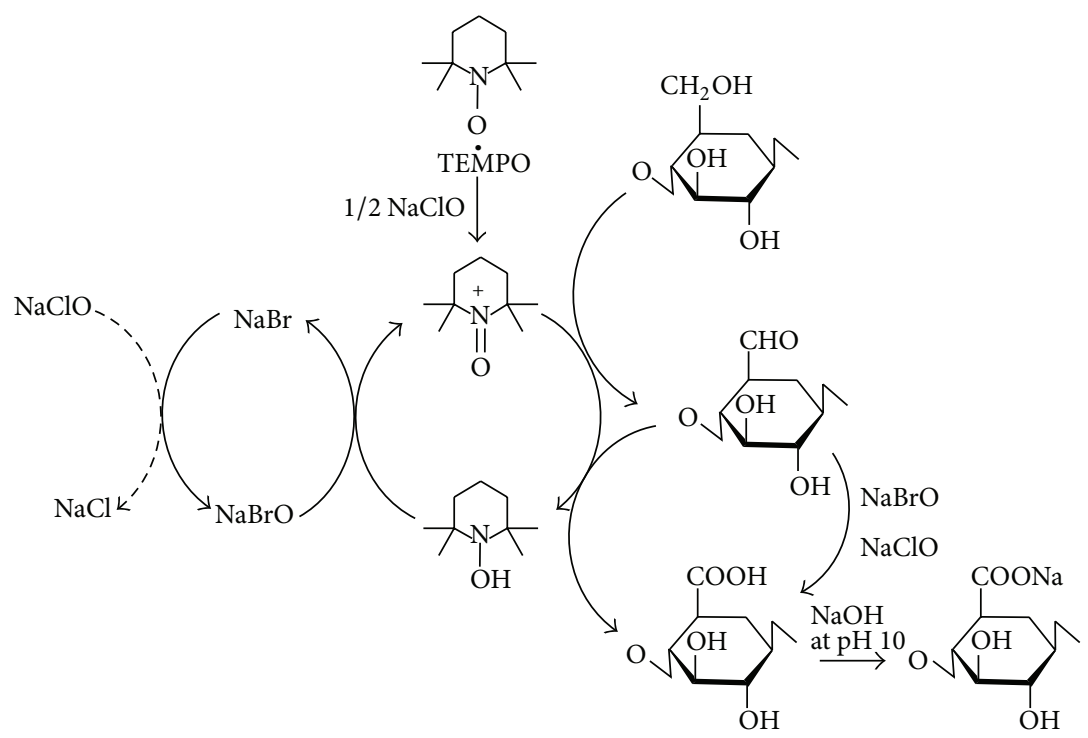

FIGURE 3: Regioselective oxidation of C6 primary hydroxyls of cellulose to C6 carboxylate groups by $\mathrm{TEMPO} / \mathrm{NaBr} / \mathrm{NaClO}$ oxidation in water at $\mathrm{pH} 10-11[19]$.

with its porosity, nanopaper's tensile strength relates directly to its fabrication process [25], and the stress-strain curves for nanopaper were compared in Figure 5(d), Polyethylene terephthalate (PET) and regenerated cellulose film (RCF). The nanopaper has higher tensile stress than PET, but a lower strain-to-failure. The high mechanical strength gives nanopaper huge potential in roll-to-roll printed electronics.

4.2. Optical Properties. Other fascinating properties of CNFs paper are ultrahigh transparency and adjustable optical haze. The regular paper is nontransparent, but the CNFs paper can be transparent when it is fabricated with nanofibers. This property makes the nanopaper become a possibility as a transparent substrate. The maximum transparency among all current reports on glass and plastic is about $90 \%$ but with a very low optical haze $(<20 \%)[15,26,27]$. Optical haze quantifies the percent of the transmitted light that diffusely scatters, which is preferable in solar cell applications [28, 29]. Optical transparency and haze are inversely proportional values in various papers. Plastic has transparency of about $90 \%$ but with an optical haze of less than $1 \%$ [30]. Fang et al. [31] recently investigated highly transparent and hazy paper with hybrid cellulose. They research a novel 


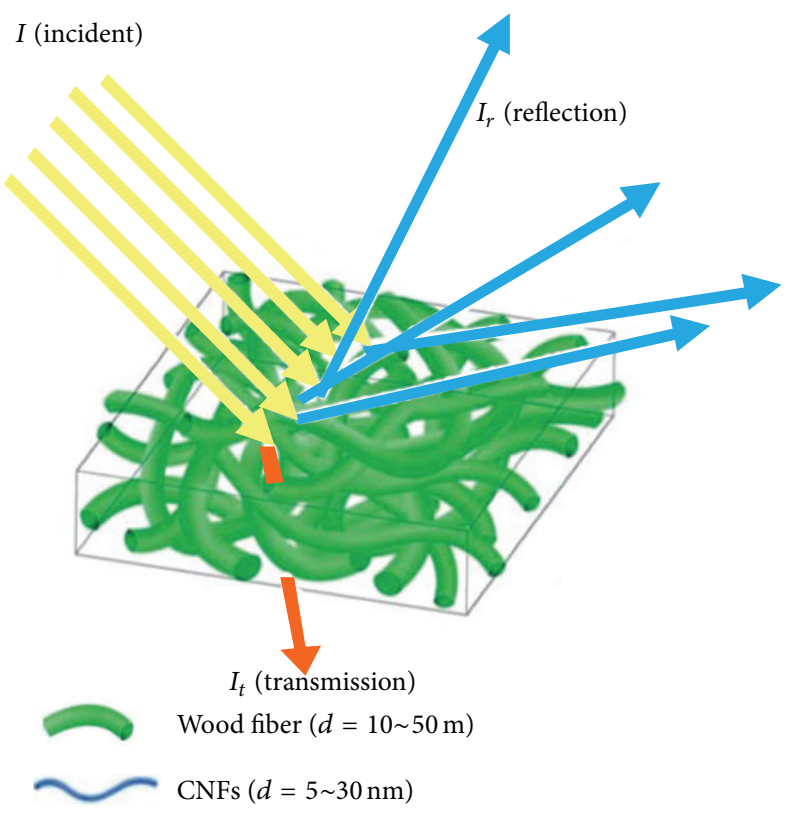

(a)

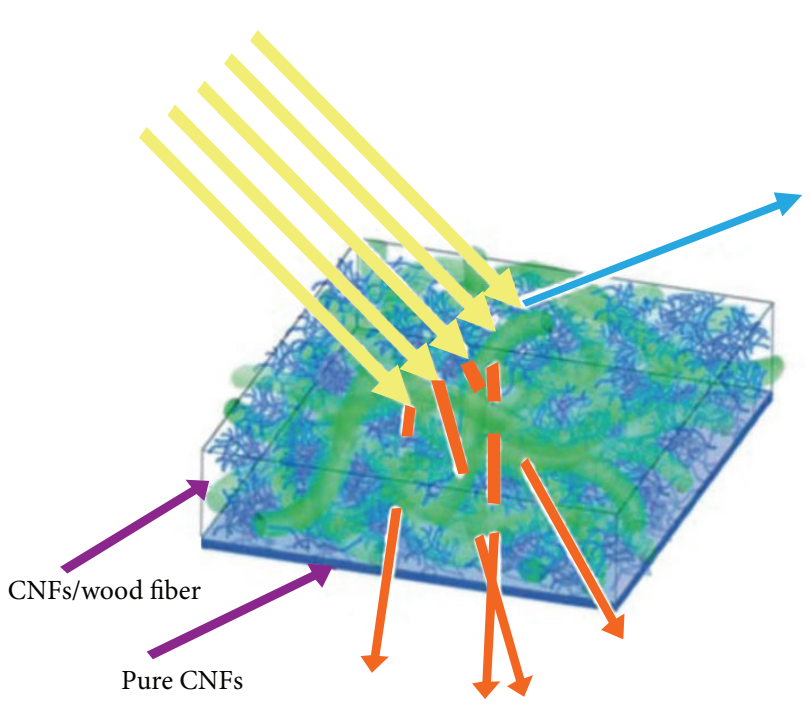

(b)

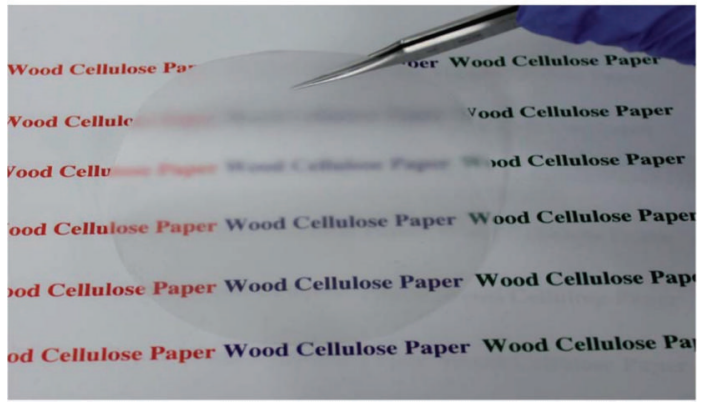

(c)

FIgURE 4: (a) Opaque cellulosic paper made of wood fibers. (b) Transparent hybrid paper consisting of two layers: the bottom layer is made of CNFs and the top layer is produced by saturating CNFs into the pores among the network of wood fibers. The width of the wood fiber and CNFs is $10-50 \mathrm{~mm}$ and 5-30 nm, respectively. (c) Image of the designed all-cellulose hybrid transparent paper with thickness of $70 \mu \mathrm{m}$ [23].

transparent paper based on wood fibers, which has an ultrahigh optical transparency $(\sim 96 \%)$ and simultaneously an ultrahigh optical haze $(\sim 60 \%)$.

Nogi et al's experiment results [5] are shown in Figure 6(a). The dried sheet was not optically transparent but translucent and has plastic film-like appearance indicating that light scattering in the bulk sheet is significantly suppressed. In other words, the lack of transparency seemed to be caused by surface light scattering. When the sheet is polished using emery paper (4000 grit followed by 15000 grit), it becomes transparent. The regular light transmittance levels of the sheet before and after polishing are compared in Figure 6(a) (sheet thicknesses are $60 \mu \mathrm{m}$ before and $55 \mu \mathrm{m}$ after polishing, resp.). The light transmittance of the CNFs sheet upon polishing reached $71.6 \%$, including surface reflection (Fresnel's reflection) at a wavelength of $600 \mathrm{~nm}$. Despite the plastic-like transparency, the sheet is as foldable as conventional paper (Figure 6(b)).
The achievement of optical transparency in the CNFs paper by smoothing the surface suggests various approaches for making functional transparent cellulose sheets. Smooth surfaces can be obtained by the lamination of optically transparent plastics, such as polycarbonate films, on the nanofiber paper by exploiting the thermal softening temperature of thermoplastics while avoiding thermal deterioration of cellulose (Figure 7(a)). This would greatly contribute to the simplification of the roll-to-roll process as well. Another approach would be to deposit transparent resins on the surface (Figure 7(b)), or even transparent conductive materials, like indium tin oxide (ITO), using a spin-coater. Ink-jet printers may allow the drawing of precise transparent and functional patterns on the sheet via the addition of functional nanoelements to the ink (Figure 7(c)). As cellulose is highly hygroscopic, transparent-CNFs sheets without chemical modification are liable to dimensional instability [33]. These surface-smoothing approaches would not only impart 


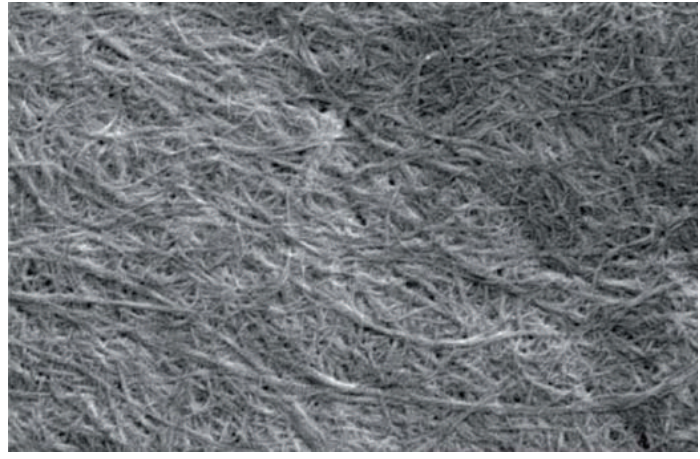

(a)

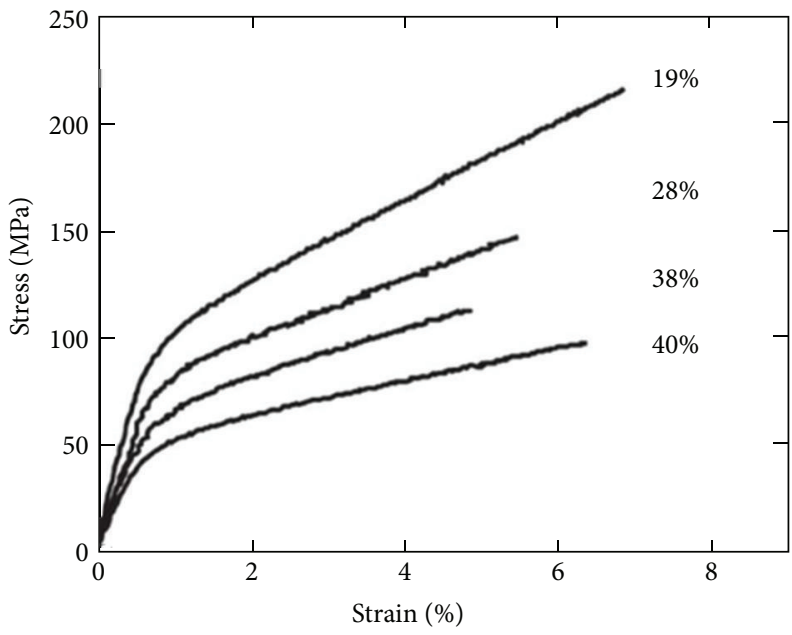

(c)

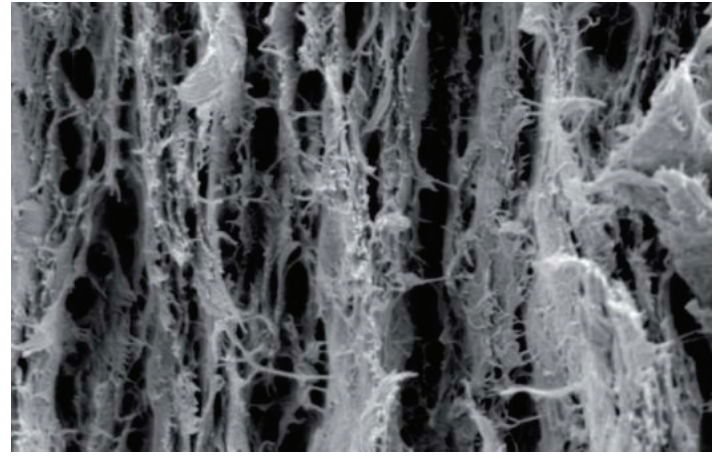

(b)

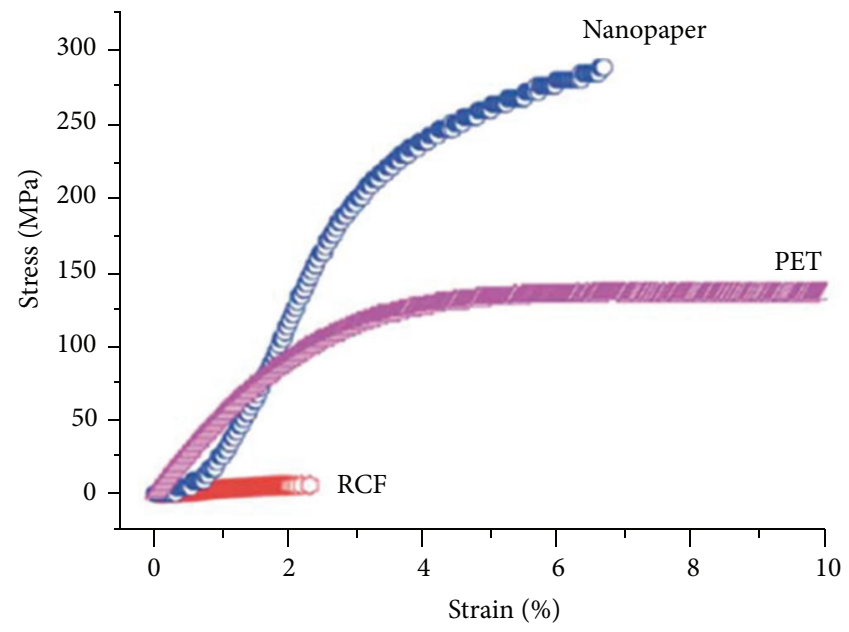

(d)

FIGURE 5: (a) SEM image of a nanopaper surface. (b) SEM image of a nanopaper cross-section. (c) Stress-strain curves for nanopaper with different porosities. Cellulose with degree of polymerization (DP) 800 was used. (d) Comparison of tensile strength for different transparent substrate, including PET, regenerated cellulose film, and nanopaper. Note that the maximum strain for PET is up to $81 \%$ [32].

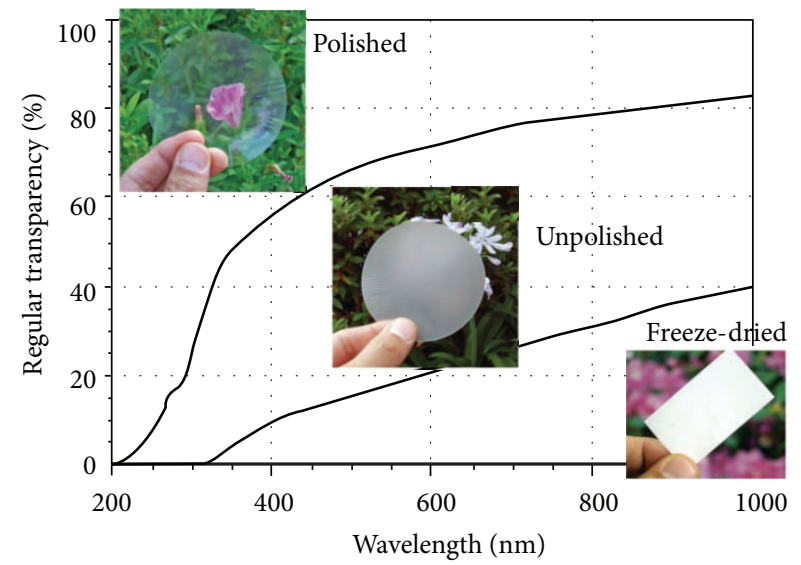

(a)

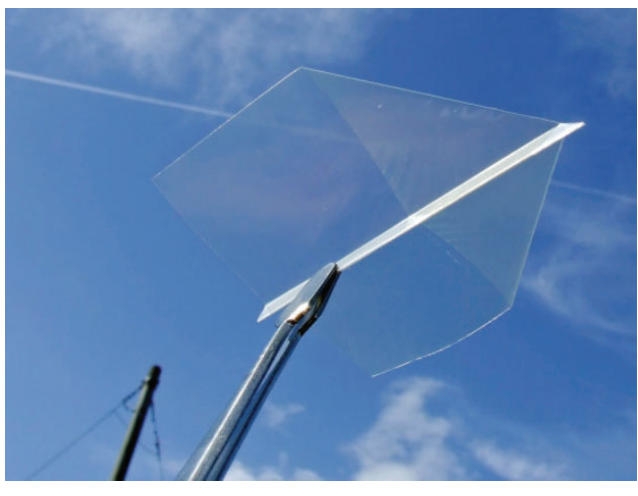

(b)

FIGURE 6: (a) Light transmittance of the CNFs sheets. The thicknesses of the oven-dried nanofiber sheet were $60 \mu \mathrm{m}$ before and $55 \mu \mathrm{m}$ after polishing. (b) The sheet is as foldable as conventional paper [5]. 


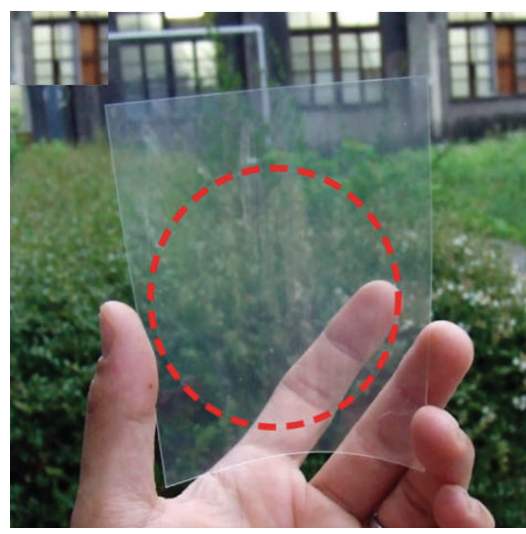

(a)

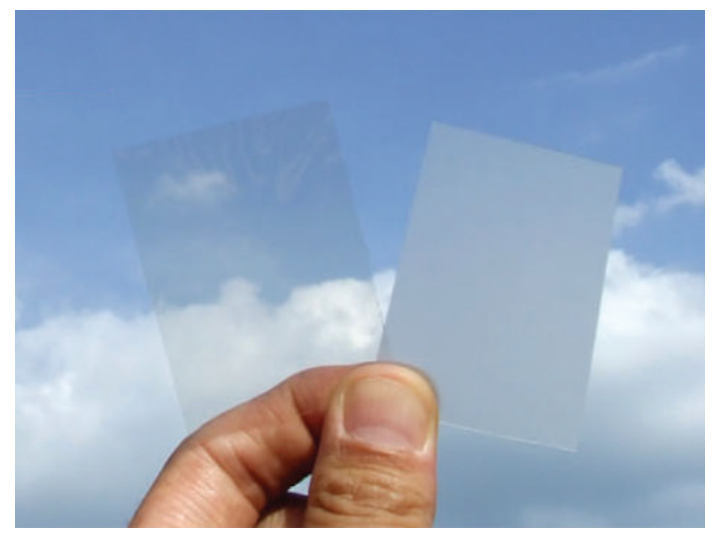

(b)

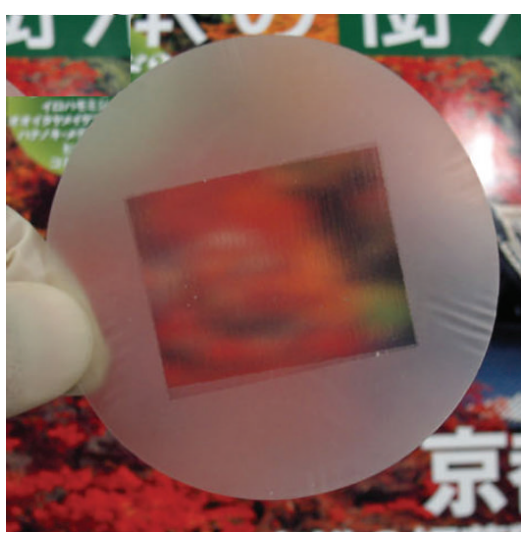

(c)

FIGURE 7: The approaches to preparing functional transparent cellulose sheets. (a) Lamination of optically transparent plastics (inside the red circle). (b) Deposition of transparent resins on the surface of cellulose sheets (left: surface-coated sheet, right: uncoated sheet). (c) Drawing of transparent patterns on the sheet using a domestic ink-jet printer [5].

high optical transparency but also act as moisture barriers to the CNFs sheets. The optical haze and transmittance of transparent paper can be tuned by the porosity and the size of CNFs. It is critical to design transparent paper with tunable optical properties with low-cost processes.

\subsection{Thermal Expansion and Thermal Durability Properties.} Most electronic devices sustain a heat treatment at a temperature of approximately $300-500^{\circ} \mathrm{C}$ to obtain the optimal performance [32]. The devices must be fabricated on inorganic silicon or glass substrates, which have high thermal durability and low thermal expansion, so the thermal properties of CNFs paper are very important for its application in optoelectronic devices [34]. Thus CNFs paper must endure temperature during the process without wrinkling, tinting, or thermal decomposing. The DP of original cellulose begins to decrease around $250^{\circ} \mathrm{C}$, and extensive degradation of cellulose occurs when the temperature is over $300^{\circ} \mathrm{C}$ [35]. Thermal chemical degradation and coefficient of thermal expansion (CTE) of transparent paper can be tested by thermogravimetric analysis (TGA) and thermomechanical analysis (TMA).
The CNFs paper is different from regular paper due to a change of particle type and surface modification; there is a decrease in the initial decomposed temperature of cellulose that was observed when it was tested by TGA [36]. Figure 8(a) displays the TGA curves of original cellulose. Fukuzumi et al. [37] found the thermal decomposition temperature decreased with an introduction of sodium carboxyl group into cellulose by TGA. Hsieh et al. [38] presented only a cellulose nanopaper with a high thermal stability that can be used to fabricate conductive circuits in 2013. As shown aforementioned CNFs and pulp paper were stable, but these properties were altered for photo paper when it was exposed to different processing temperatures and treatment times (Figure 8(b)). The optical transmittance of transparent paper remained unchanged, and no obvious change of the surface morphology was observed after it was treated at $150^{\circ} \mathrm{C}$ for different processing times (Figure 8(c)).

The CTE of crystalline cellulose in the axial direction is around $0.1 \mathrm{ppm} \mathrm{K} \mathrm{K}^{-1}$, which is more than an order of magnitude lower than plastics, most metals, and ceramics $[39,40]$. The optically transparent paper made of CNFs has a CTE of $<8.5 \mathrm{ppm} \mathrm{K}^{-1}$, which is much lower than plastic (CTE, $50 \mathrm{ppm} \mathrm{K}^{-1}$ ). This is desirable for electronic devices 


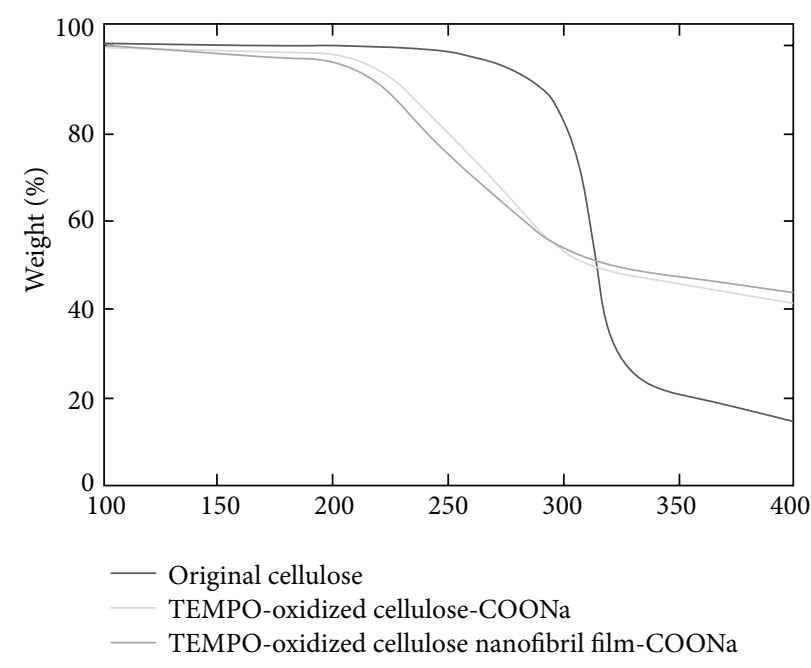

(a)
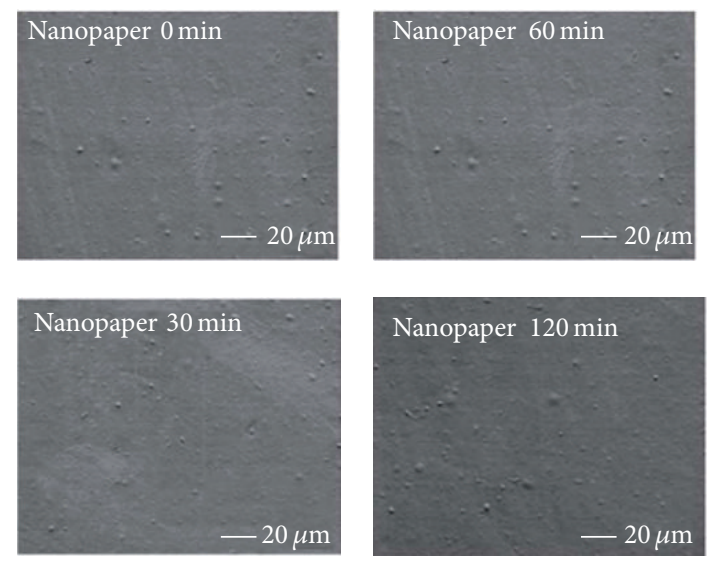

(c)

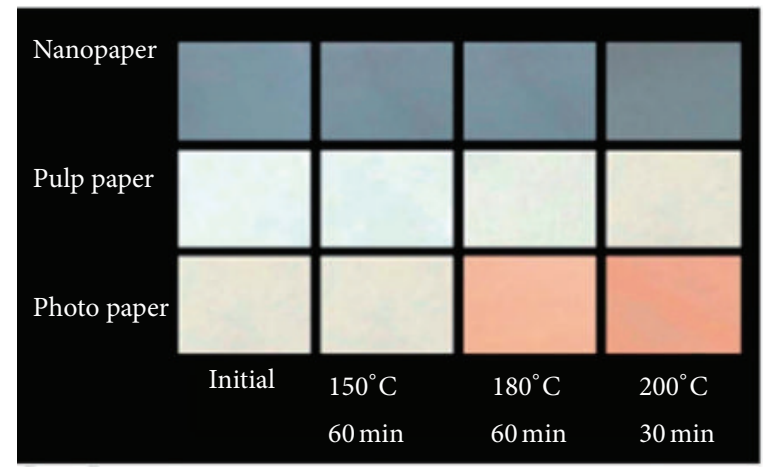

(b)

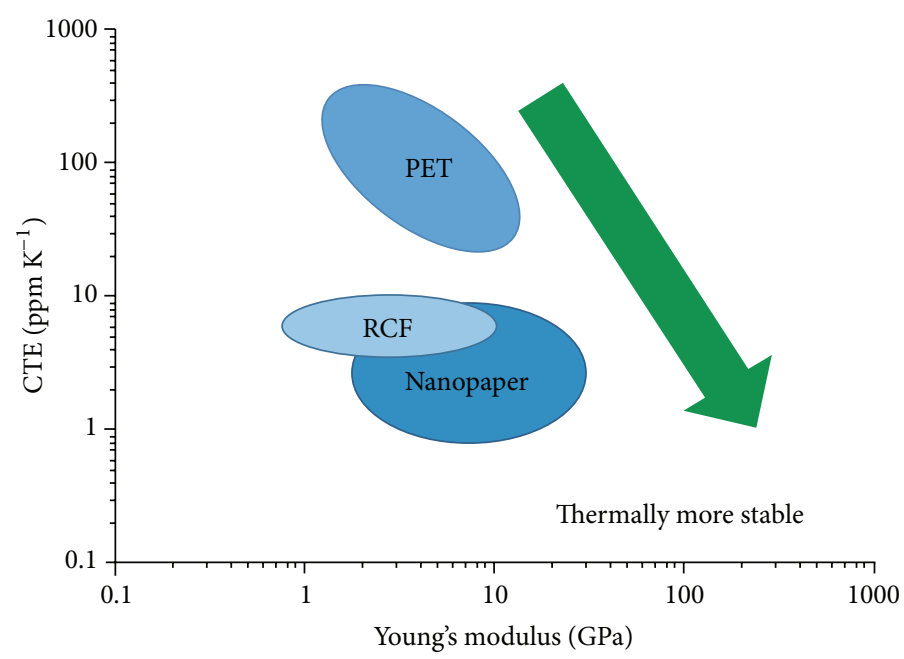

(d)

FIGURE 8: (a) TGA of original cellulose, TEMPO-oxidized cellulose with sodium carboxyl group, and TEMPO-oxidized cellulose film with sodium carboxyl group. (b) Digital image of photo paper, pulp paper, and nanopaper under the treatment of various temperatures. (c) SEM images of the surface of nanopaper when it is exposed to $150^{\circ} \mathrm{C}$ for different time. (d) Coefficient of thermal expansion versus Young's modulus [32].

since it can maintain the dimensional stability under thermal processing condition [5]. The Ashby plot of CTE versus Young's modulus is shown in Figure 8(d) [41]. CNFs paper shows lowest CTE compared to regenerated cellulose film (RCF) and PET, which has the potential to replace current plastic to fabricate flexible electronics.

\section{The CNFs for Optoelectronic Conversion and Energy Storage}

Optoelectronic devices, such as mobile phones, displays, organic light-emitting diodes lighting (OLED), and solar cells, are manufactured by process that involves extreme conditions, such as high temperatures, high vacuum, which must be fabricated on glass or inorganic silicon substrates and have high thermal durability and low thermal expansion, so these devices are heavy and inflexible. In order to fabricate flexible, lightweight, high thermal expansion and low thermal durability, paper substrates have been attracting attention for consumer electronics applications.

5.1. Energy Storage with Conductive Paper. The energy storage system involving liquid electrolytes can utilize our CNFs paper because its interconnected porosity allows fast access of ionic species to the electrode surfaces [7]. Researchers try to render electrical conduction in CNFs paper, so the conducting materials such as graphene [42], carbon nanotubes (CNTs) [43], and conductive metal oxide [44] can be integrated. Pushparaj et al. [45] developed a method to dissolve unmodified cellulose fibers in a room-temperature ionic liquid, 1-buty1,3-methylimidazolium chloride. The cellulose solution was then coated onto vertically grown CNTs to 


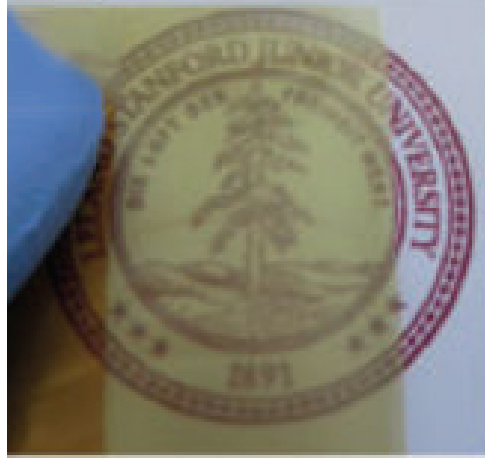

Conductive metal oxide

(a)

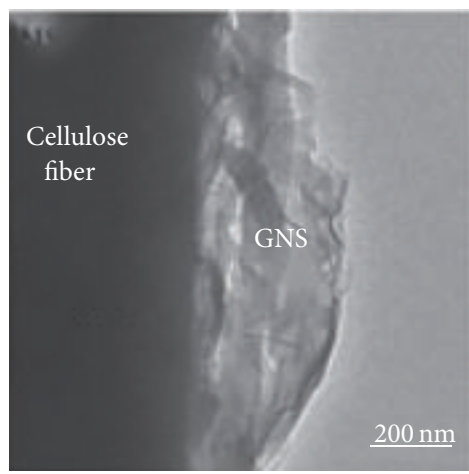

Graphene

(b)

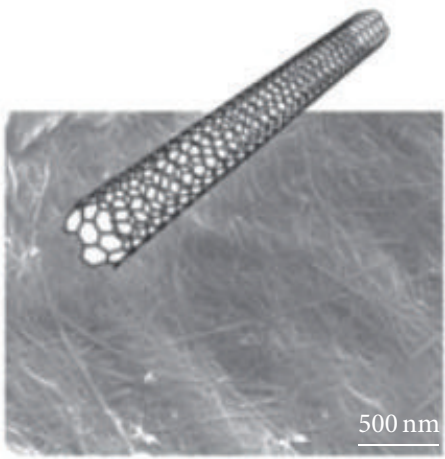

Carbon nanotubes

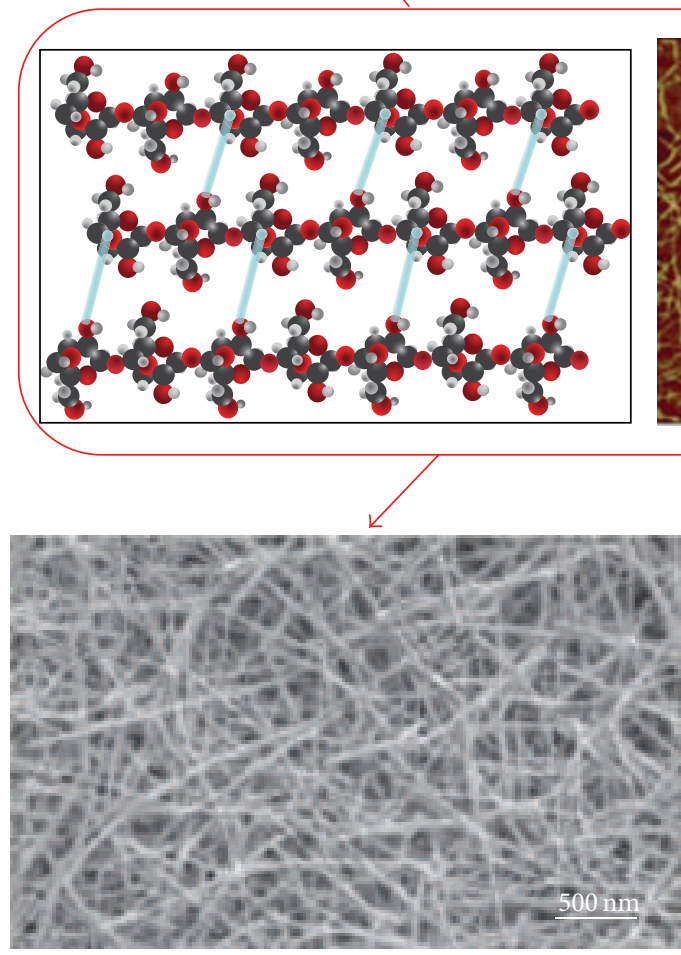

Silver nanowires

(d)

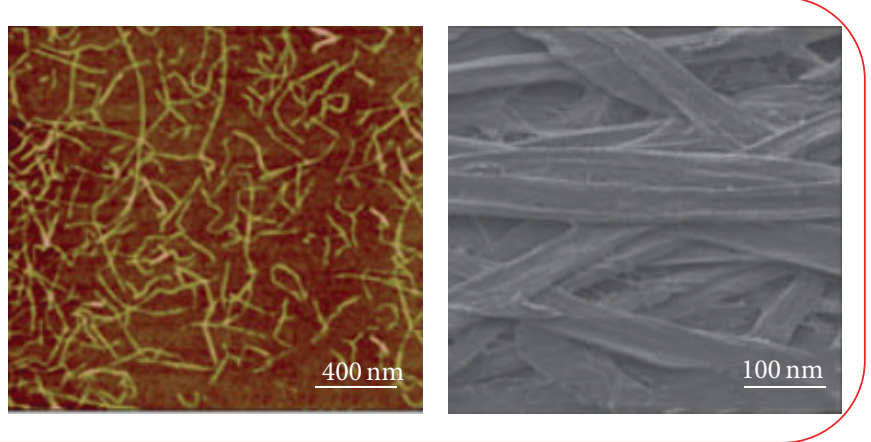

(f)

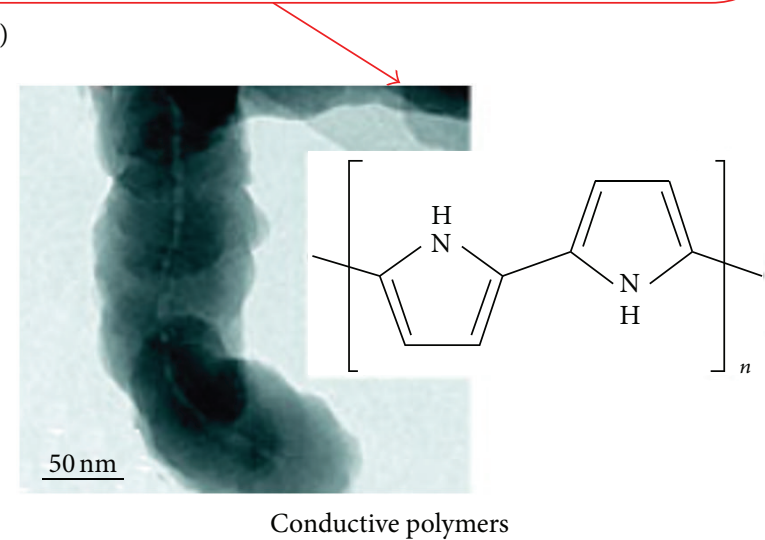

(e)

Figure 9: Diagram showing conductive materials, such as (a) tin doped indium oxide (ITO), (b) graphene, (c) carbon nanotubes, (d) silver nanowires, (e) and conductive polymers, (f) ranging from the molecular level to nanofibrils and the microfiber level [7].

form the conductive paper, which can be used as an electrode for super capacitors and lithium-ion batteries (Figure 9(a)).

The similarity in dimensions of the CNFs and CNTs allows uniform mixing of the two materials at the nanofibrils scale, following a highly conductive porous composite suitable for high surface area electrodes (Figure 9(b)) [46]. Conductive polymers are also widely used to coat CNFs. Polypyrrole has been found to wet cellulose very well, and polymerization of pyrroles on the surface of cellulose turned out to be conformal coatings of polypyrrole on the CNFs [47]. Coating of CNFs aerogel was demonstrated by using a polyaniline-dodecyl benzene sulfonic acid doped solution in toluene [48].
Nonunique Meyer rod coating of CNTs ink onto commercially available photocopy paper was shown to be highly effective in conductive paper with a sheet resistance of around $10 \Omega /$ sq. The high conductivity was attributed to the strong solvent absorption properties of the porous paper structure and the conformal coating of flexible CNTs on the CNFs to form continuous electrical conduction pathways. Conductive paper made from CNFs also demonstrates excellent mechanical properties.

Due to the hydrophilicity of CNFs, conductive paper as electrodes has been widely used in supercapacitor. Unmodified CNTs are hydrophobic, and their applications in super capacitors have been impeded by poor electrolyte wetting. 


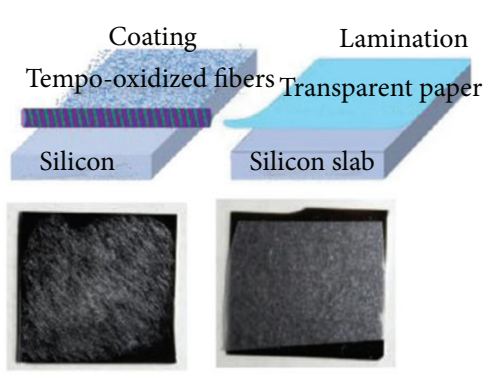

(a)

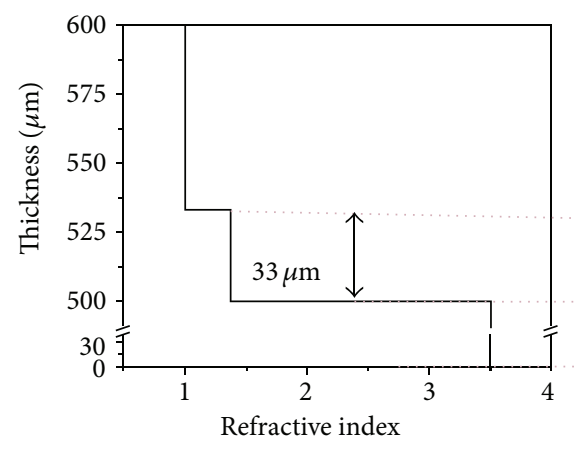

(c)

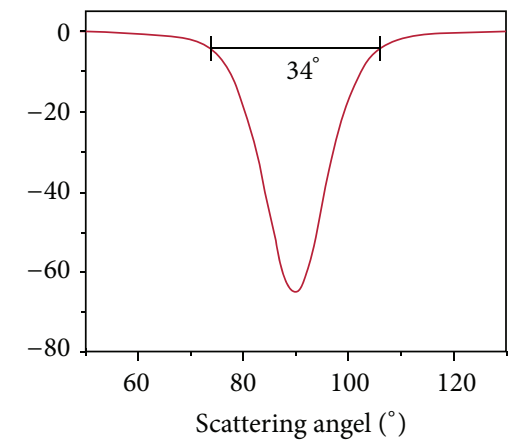

(e)

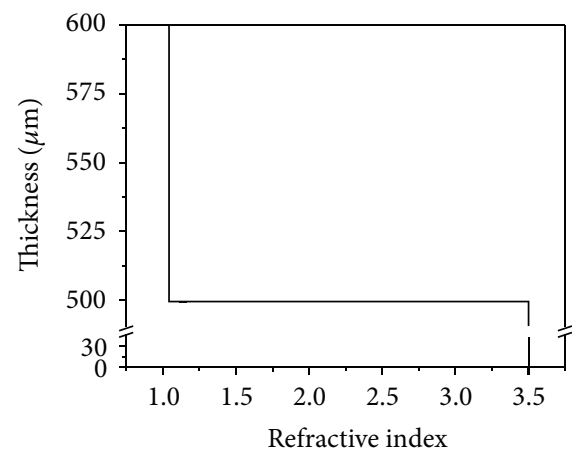

(b)

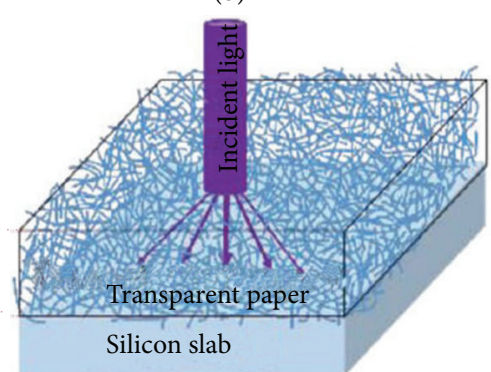

(d)

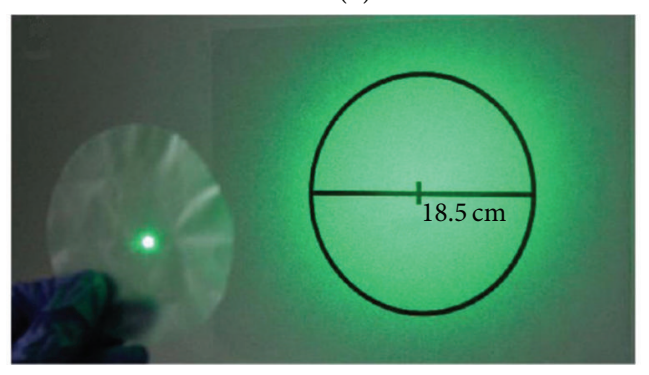

(f)

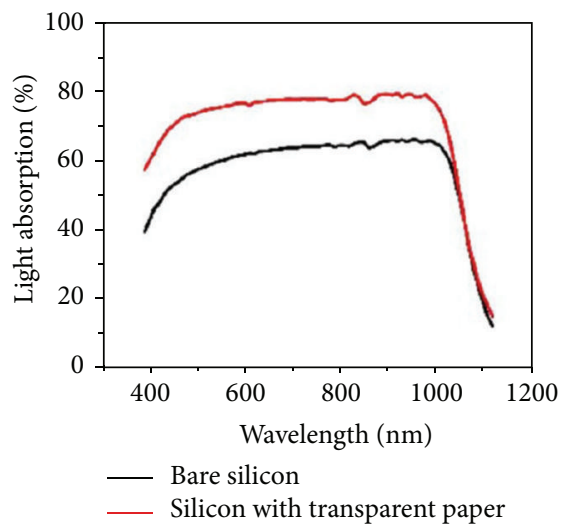

(g)

Figure 10: (a) Schematics and images of cellulose-deposited silicon slab. Top left: a schematic structure of wood fibers deposited on a silicon slab by Meyer rod coating. Top right: a schematic of transparent paper attached on silicon slab by lamination. Bottom left: TEMPO-oxidized wood fibers deposited on a silicon slab. Bottom right: transparent paper with a thickness of $33 \mu \mathrm{m}$ attached on a silicon slab. (b) The effective refractive index profiles of the interfaces between air and silicon slab. (c) The effective refractive index profiles of $33 \mu \mathrm{m}$ cellulose deposited on a silicon slab. (d) A schematic diagram of transparent paper and its light scattering behavior. (e) Scattering angular distribution with an arbitrary $y$-axis unit for transparent paper. The maximum scattering angle is $34^{\circ}$. (f) A photo showing the light scattering effect of transparent paper when a laser with a diameter of $0.4 \mathrm{~cm}$ passes though transparent paper. ( $\mathrm{g}$ ) The light absorption of transparent paper laminated on a silicon slab [31]. 
By using CNFs as a substrate for the carbon matrix, aqueous electrolyte can be easily absorbed into the electrode, providing intimate contact between the carbon electrode and electrolyte [49]. For lithium-ion battery applications, the use of conductive nanofiber paper offers new opportunities in fabricating highly flexible electrodes.

Zheng et al. [7] studied the new development of CNFs and discuss how to combine CNFs with other nanomaterials to expand the application in supercapacitor. They utilize the regular paper with high porosity that can suck conductive ink as the substrate and then coat CNT directly on it. It is found that the paper coated with CNT as a supercapacitor electrode demonstrated excellent performance with a capacitance of $200 \mathrm{~F} / \mathrm{g}$ and stable capability for more than 40000 cycles. The electrode of graphene-nanofiber paper also boasted a good capacitance of $120 \mathrm{~F} / \mathrm{g} ; 99 \%$ maintained up to 5000 cycles. They also provided another simple method to fabricate super capacitors, taking graphite pencil/nanofiber paper for electrode, water as electrolyte capacitor. The capacitance is around $2.3 \mathrm{mF} / \mathrm{m}^{2}$ after 15000 cycles of charge/discharge, and this device maintained over $90 \%$ initial value.

CNFs can be used for energy storage base-materials, due to their porous structure promoting the diffusion of ions. Gui et al. [50] have given a strong proof for this conclusion by comparing the base-material of supercapacitor with the holes without holes. They use solution dip and electrodeposition method to prepare hybrid electrode of paper/CNTs $/ \mathrm{MnO}_{2}$ (P-CM), paper/ $/ \mathrm{Al}_{2} \mathrm{O}_{3} / \mathrm{CNTs} / \mathrm{MnO}_{2}$ (P$\mathrm{ACM}$ ), and paper/CNTs/ $\mathrm{MnO}_{2} / \mathrm{CNTs}$ (P-CMC). However, for the $\mathrm{Al}_{2} \mathrm{O}_{3}$ coated CNFs paper, owing to the nonporous $\mathrm{Al}_{2} \mathrm{O}_{3}$ layer, the pores on the surface of CNFs will be blocked. Comparing the $\mathrm{P}-\mathrm{CM}$ and $\mathrm{P}-\mathrm{ACM}$, the $\mathrm{P}-\mathrm{CM}$-base super capacitor has better electrochemical performance than the latter, and CNFs are very conducive to the ion diffusion. Furthermore, comparing the P-CM and P-CMC, P-CMCbased electrode has superior capacitive performance for its dual ion diffusion pathway. The nanofiber paper-based electrode demonstrates excellent cycling performance, and the retention of its capacity is $85 \%$ up to 50000 cycles. This study illustrated fully that hole cellulose fiber is very conducive to the ion diffusion and it is a great potential material of super capacitor.

5.2. CNFs for Optoelectronic Conversion. A new outcome has been reported by Fang et al. [31] novel nanostructured paper with ultrahigh transparency and ultrahigh haze for solar cells. Because it is a kind of natural materials, this CNFs paper is more environment friendly than traditional substrates such as glass and plastic [51-53]. The maximum transparency of regular substrates is high about $90 \%$, but its optical haze is very low $(<20 \%)$, while CNFs paper has not only ultrahigh optical transparency ( 96\%), but also ultrahigh optical haze $(\sim 60 \%)$.

The CNFs paper with ultrahigh transmittance and high transmission haze has potential applications in solar cells [31]. The light scattering effect of transparent paper can improve the path of light traveling through the active layers of thin film solar cells resulting in an enhanced light absorption. An experiment is implemented that, as shown in Figure 10(a), TEMPO-oxidized wood fibers were directly coated onto the surface of a silicon slab and transparent paper laminated onto the surface of silicon using CNFs as a binder to analyze any resulting enhancement of light absorption in the silicon. The possible mechanisms are as follows: (1) the index of transparent paper that is between the values for the $\mathrm{Si}$ substrate and air, which can effectively decrease the index contrast and lower the reflection for light entering from air to $\mathrm{Si}$ (Figures 10(b) and 10(c)); (2) a large light forward scattering effect of transparent paper, which can increase the path length of light in the Si layer (Figure 10(d)); and (3) an ultrahigh optical transparency up to $96 \%$ of transparent paper. These effects make transparent paper fundamentally better than plastic substrates for thin film solar cells.

The direct incident light is scattered as it propagates through the transparent paper, generating a high transmission haze (Figure 10(d)). To quantitatively explain the light scattering effect of transparent paper, an optical setup consisting of a rotating light detector is applied to measure the angular distribution of transmitted light. Light passing through transparent paper exhibits high diffuse scattering with an expected inverse Gaussian-like pattern (Figure 10(e)). Transparent paper delivers a maximum scattering angle of $34^{\circ}$. The light scattering effect is also visualized in Figure 10(f). A laser with a wavelength of $532 \mathrm{~nm}$ and a beam diameter of $0.4 \mathrm{~cm}$ passes through transparent paper and forms a larger illuminated circular area on the surface of the target with a diameter of over $18.5 \mathrm{~cm}$. The same experiment is also applied to glass and PET to illustrate the light scattering effect, and because the transmission haze of PET and glass is lower than $1 \%$, the transmitted light is scattered only slightly as visualized by a smaller illuminated area on the target behind the transparent paper. Figure $10(\mathrm{~g})$ indicates the light absorption of transparent paper laminated on a silicon slab. Compared to a bare silicon slab, there is enhanced light trapping in all the prepared samples by approximately $10-18 \%$ from 400 to $1000 \mathrm{~nm}$. These results show that (1) both TEMPO-oxidized wood fibers and transparent paper can enhance the broadband absorption efficiency of the silicon slab and (2) transparent paper or TEMPO-treated wood fibers can be applied to a silicon slab with simple coating, dipping, or lamination that depends on the specific application desired.

\section{Conclusions}

In this paper, we mainly review the preparation structure, properties, and applications in optoelectronic devices of CNFs in latest research. CNFs paper has huge potential to replace traditional materials such as glasses and plastic. However, there are tremendous challenges [32] including (1) transparent paper nanofabrication challenges with an aim of much higher speed and much lower energy consumption; (2) substrate property improvement including the shape stability, water absorption, and barrier properties to water and oxygen; (3) printing process development and improved properties of printed materials; (4) device fabrication, reliability, and 
integrations with roll-to-roll processing. We believe that these problems can be overcome sooner or later. For device applications, cellulose nanopaper will give us more flexibility to tune the substrate properties for different applications, such as display, solar cell, and energy storage.

\section{Conflict of Interests}

The authors declare that there is no conflict of interests regarding the publication of this paper.

\section{Acknowledgments}

The authors thank the support of the New-Century Training Program Foundation for the Talents by the Ministry of Education of China (NCET-11-0979), National Natural Science Foundation of China (no. 31370564), and Graduate Student Innovation Fund of Central South University of Forestry and Technology (no. CX2014B20).

\section{References}

[1] N. Komoda, M. Nogi, K. Suganuma, H. Koga, and K. Otsuka, "Silver nanowire antenna printed on polymer and paper substrates," in Proceedings of the 12th IEEE International Conference on Nanotechnology (NANO '12), pp. 1-5, IEEE, August 2012.

[2] F. Eder, H. Klauk, M. Halik, U. Zschieschang, G. Schmid, and C. Dehm, "Organic electronics on paper," Applied Physics Letters, vol. 84, no. 14, pp. 2673-2675, 2004.

[3] A. Russo, B. Y. Ahn, J. J. Adams, E. B. Duoss, J. T. Bernhard, and J. A. Lewis, "Pen-on-paper flexible electronics," Advanced Materials, vol. 23, no. 30, pp. 3426-3430, 2011.

[4] Z. Weng, Y. Su, D. Wang, F. Li, J. Du, and H. Cheng, "Graphene-cellulose paper flexible supercapacitors," Advanced Energy Materials, vol. 1, no. 5, pp. 917-922, 2011.

[5] M. Nogi, S. Iwamoto, A. N. Nakagaito, and H. Yano, "Optically transparent nanofiber paper," Advanced Materials, vol. 21, no. 16, pp. 1595-1598, 2009.

[6] Y. Okahisa, A. Yoshida, S. Miyaguchi, and H. Yano, "Optically transparent wood-cellulose nanocomposite as a base substrate for flexible organic light-emitting diode displays," Composites Science and Technology, vol. 69, no. 11-12, pp. 1958-1961, 2009.

[7] G. Zheng, Y. Cui, E. Karabulut, L. Wågberg, H. Zhu, and L. $\mathrm{Hu}$, "Nanostructured paper for flexible energy and electronic devices," MRS Bulletin, vol. 38, no. 4, pp. 320-325, 2013.

[8] J. I. Morán, V. A. Alvarez, V. P. Cyras, and A. Vázquez, "Extraction of cellulose and preparation of nanocellulose from sisal fibers," Cellulose, vol. 15, no. 1, pp. 149-159, 2008.

[9] M. A. Martins, E. M. Teixeira, A. C. Corrêa, M. Ferreira, and L. H. C. Mattoso, "Extraction and characterization of cellulose whiskers from commercial cotton fibers," Journal of Materials Science, vol. 46, no. 24, pp. 7858-7864, 2011.

[10] A. N. Nakagaito and H. Yano, "The effect of morphological changes from pulp fiber towards nano-scale fibrillated cellulose on the mechanical properties of high-strength plant fiber based composites," Applied Physics A, vol. 78, no. 4, pp. 547-552, 2004.

[11] A. Chakraborty, M. Sain, and M. Kortschot, "Cellulose microfibrils: a novel method of preparation using high shear refining and cryocrushing," Holzforschung, vol. 59, no. 1, pp. 102-107, 2005.
[12] S. Janardhnan and M. M. Sain, "Isolation of cellulose microfibrils—an enzymatic approach," Bioresources, vol. 1, no. 2, pp. 176-188, 2007.

[13] M. Pääkkö, M. Ankerfors, H. Kosonen et al., "Enzymatic hydrolysis combined with mechanical shearing and highpressure homogenization for nanoscale cellulose fibrils and strong gels," Biomacromolecules, vol. 8, no. 6, pp. 1934-1941, 2007.

[14] T. Saito, Y. Nishiyama, J. Putaux, M. Vignon, and A. Isogai, "Homogeneous suspensions of individualized microfibrils from TEMPO-catalyzed oxidation of native cellulose," Biomacromolecules, vol. 7, no. 6, pp. 1687-1691, 2006.

[15] H. Fukuzumi, T. Saito, T. Iwata, Y. Kumamoto, and A. Isogai, "Transparent and high gas barrier films of cellulose nanofibers prepared by TEMPO-mediated oxidation," Biomacromolecules, vol. 10, no. 1, pp. 162-165, 2009.

[16] T. Saito, M. Hirota, N. Tamura et al., "Individualization of nanosized plant cellulose fibrils by direct surface carboxylation using TEMPO catalyst under neutral conditions," Biomacromolecules, vol. 10, no. 7, pp. 1992-1996, 2009.

[17] W. Adam, C. R. Saha-Möller, and P. A. Ganeshpure, "Synthetic applications of nonmetal catalysts for homogeneous oxidations," Chemical Reviews, vol. 101, no. 11, pp. 3499-3548, 2001.

[18] P. L. Bragd, A. C. Besemer, and H. van Bekkum, "Bromidefree TEMPO-mediated oxidation of primary alcohol groups in starch and methyl $\alpha$-D-glucopyranoside," Carbohydrate Research, vol. 328, no. 3, pp. 355-363, 2000.

[19] A. Isogai, T. Saito, and H. Fukuzumi, "TEMPO-oxidized cellulose nanofibers," Nanoscale, vol. 3, no. 1, pp. 71-85, 2011.

[20] W. F. Bailey, J. M. Bobbitt, and K. B. Wiberg, "Mechanism of the oxidation of alcohols by oxoammonium cations," Journal of Organic Chemistry, vol. 72, no. 12, pp. 4504-4509, 2007.

[21] S. Goldstein and A. Samuni, "Kinetics and mechanism of peroxyl radical reactions with nitroxides," The Journal of Physical Chemistry A, vol. 111, no. 6, pp. 1066-1072, 2007.

[22] A. Isogai and Y. Kato, "Preparation of polyuronic acid from cellulose by TEMPO-mediated oxidation," Cellulose, vol. 5, no. 3, pp. 153-164, 1998.

[23] Z. Fang, H. Zhu, C. Preston et al., "Highly transparent and writable wood all-cellulose hybrid nanostructured paper," Journal of Materials Chemistry C, vol. 1, no. 39, pp. 6191-6197, 2013.

[24] M. A. Hubbe, J. J. Pawlak, and A. A. Koukoulas, "Paper's appearance: a review," Bioresources, vol. 3, no. 2, pp. 627-665, 2008.

[25] H. Sehaqui, M. Allais, Q. Zhou, and L. A. Berglund, "Wood cellulose biocomposites with fibrous structures at micro- and nanoscale," Composites Science and Technology, vol. 71, no. 3, pp. 382-387, 2011.

[26] H. Zhu, S. Parvinian, C. Preston, O. Vaaland, Z. Ruan, and L. $\mathrm{Hu}$, "Transparent nanopaper with tailored optical properties," Nanoscale, vol. 5, no. 9, pp. 3787-3792, 2013.

[27] I. Siró, D. Plackett, M. Hedenqvist, M. Ankerfors, and T. Lindström, "Highly transparent films from carboxymethylated microfibrillated cellulose: the effect of multiple homogenization steps on key properties," Journal of Applied Polymer Science, vol. 119, no. 5, pp. 2652-2660, 2011.

[28] Y. Chiba, A. Islam, Y. Watanabe, R. Komiya, N. Koide, and L. Han, "Dye-sensitized solar cells with conversion efficiency of 11.1\%," Japanese Journal of Applied Physics, vol. 45, no. 24-28, part 2, pp. L638-L640, 2006. 
[29] M. Berginski, J. Hüpkes, M. Schulte et al., "The effect of front $\mathrm{ZnO}$ : Al surface texture and optical transparency on efficient light trapping in silicon thin-film solar cells," Journal of Applied Physics, vol. 101, no. 7, Article ID 074903, 2007.

[30] W. A. MacDonald, M. K. Looney, D. Mackerron et al., "Latest advances in substrates for flexible electronics," Journal of the Society for Information Display, vol. 15, no. 12, pp. 1075-1083, 2007.

[31] Z. Fang, H. Zhu, Y. Yuan et al., "Novel nanostructured paper with ultrahigh transparency and ultrahigh haze for solar cells," Nano Letters, vol. 14, no. 2, pp. 765-773, 2014.

[32] H. Zhu, Z. Fang, C. Preston, Y. Li, and L. Hu, "Transparent paper: fabrications, properties, and device applications," Energy \& Environmental Science, vol. 7, no. 1, pp. 269-287, 2014.

[33] M. Nogi, K. Abe, K. Handa, F. Nakatsubo, S. Ifuku, and H. Yano, "Property enhancement of optically transparent bionanofiber composites by acetylation," Applied Physics Letters, vol. 89, no. 23, Article ID 233123, 2006.

[34] M. Nogi, C. Kim, T. Sugahara, T. Inui, T. Takahashi, and K. Suganuma, "High thermal stability of optical transparency in cellulose nanofiber paper," Applied Physics Letters, vol. 102, no. 18, Article ID 181911, 2013.

[35] J. B. Dahiya and K. Kumar, "Flame retardant study of cotton coated with intumescents: kinetics and effect of metal ions," Journal of Scientific and Industrial Research, vol. 68, no. 6, pp. 548-554, 2009.

[36] R. J. Moon, A. Martini, J. Nairn, J. Simonsen, and J. Youngblood, "Cellulose nanomaterials review: structure, properties and nanocomposites," Chemical Society Reviews, vol. 40, no. 7, pp. 3941-3994, 2011.

[37] H. Fukuzumi, T. Saito, Y. Okita, and A. Isogai, “Thermal stabilization of TEMPO-oxidized cellulose," Polymer Degradation and Stability, vol. 95, no. 9, pp. 1502-1508, 2010.

[38] M.-C. Hsieh, C. Kim, M. Nogi, and K. Suganuma, "Electrically conductive lines on cellulose nanopaper for flexible electrical devices," Nanoscale, vol. 5, no. 19, pp. 9289-9295, 2013.

[39] T. Nishino, I. Matsuda, and K. Hirao, "All-cellulose composite," Macromolecules, vol. 37, no. 20, pp. 7683-7687, 2004.

[40] H. Yano, J. Sugiyama, A. N. Nakagaito et al., "Optically transparent composites reinforced with networks of bacterial nanofibers," Advanced Materials, vol. 17, no. 2, pp. 153-155, 2005.

[41] H. Zhu, Z. Xiao, D. Liu et al., "Biodegradable transparent substrates for flexible organic-light-emitting diodes," Energy and Environmental Science, vol. 6, no. 7, pp. 2105-2111, 2013.

[42] Z. Yang, H. Sun, T. Chen, L. Qiu, Y. Luo, and H. Peng, "Photovoltaic wire derived from a graphene composite fiber achieving an $8.45 \%$ energy conversion efficiency," Angewandte Chemie, vol. 52, no. 29, pp. 7545-7548, 2013.

[43] T. Chen, S. T. Wang, Z. B. Yang et al., "Flexible, light-weight, ultrastrong, and semiconductive carbon nanotube fibers for a highly efficient solar cell," Angewandte Chemie, vol. 50, no. 8, pp. 1815-1819, 2011.

[44] X. Chen, L. Li, X. Sun et al., "Magnetochromatic polydiacetylene by incorporation of $\mathrm{Fe}_{3} \mathrm{O}_{4}$ nanoparticles," Angewandte Chemie, vol. 50, no. 24, pp. 5486-5489, 2011.

[45] V. L. Pushparaj, M. M. Shaijumon, A. Kumar et al., "Flexible energy storage devices based on nanocomposite paper," Proceedings of the National Academy of Sciences of the United States of America, vol. 104, no. 34, pp. 13574-13577, 2007.

[46] L. Hu, N. Liu, M. Eskilsson et al., "Silicon-conductive nanopaper for Li-ion batteries,” Nano Energy, vol. 2, no. 1, pp. 138-145, 2013.
[47] D. O. Carlsson, G. Nyström, Q. Zhou, L. A. Berglund, L. Nyholm, and M. Stromme, "Electroactive nanofibrillated cellulose aerogel composites with tunable structural and electrochemical properties," Journal of Materials Chemistry, vol. 22, no. 36, pp. 19014-19024, 2012.

[48] M. Pääkkö, J. Vapaavuori, R. Silvennoinen et al., "Long and entangled native cellulose I nanofibers allow flexible aerogels and hierarchically porous templates for functionalities," Soft Matter, vol. 4, no. 12, pp. 2492-2499, 2008.

[49] G. Zheng, L. Hu, H. Wu, X. Xie, and Y. Cui, "Paper supercapacitors by a solvent-free drawing method," Energy \& Environmental Science, vol. 4, no. 9, pp. 3368-3373, 2011.

[50] Z. Gui, H. Zhu, E. Gillette et al., "Natural cellulose fiber as substrate for supercapacitor," ACS Nano, vol. 7, no. 7, pp. 60376046, 2013.

[51] K. Missoum, M. N. Belgacem, and J. Bras, "Nanofibrillated cellulose surface modification: a review," Materials, vol. 6, no. 5, pp. 1745-1766, 2013.

[52] K. Missoum, M. N. Belgacem, J. Barnes, M. Brochier-Salon, and J. Bras, "Nanofibrillated cellulose surface grafting in ionic liquid," Soft Matter, vol. 8, no. 32, pp. 8338-8349, 2012.

[53] K. Missoum, J. Bras, and M. N. Belgacem, "Organization of aliphatic chains grafted on nanofibrillated cellulose and influence on final properties," Cellulose, vol. 19, no. 6, pp. 19571973, 2012. 

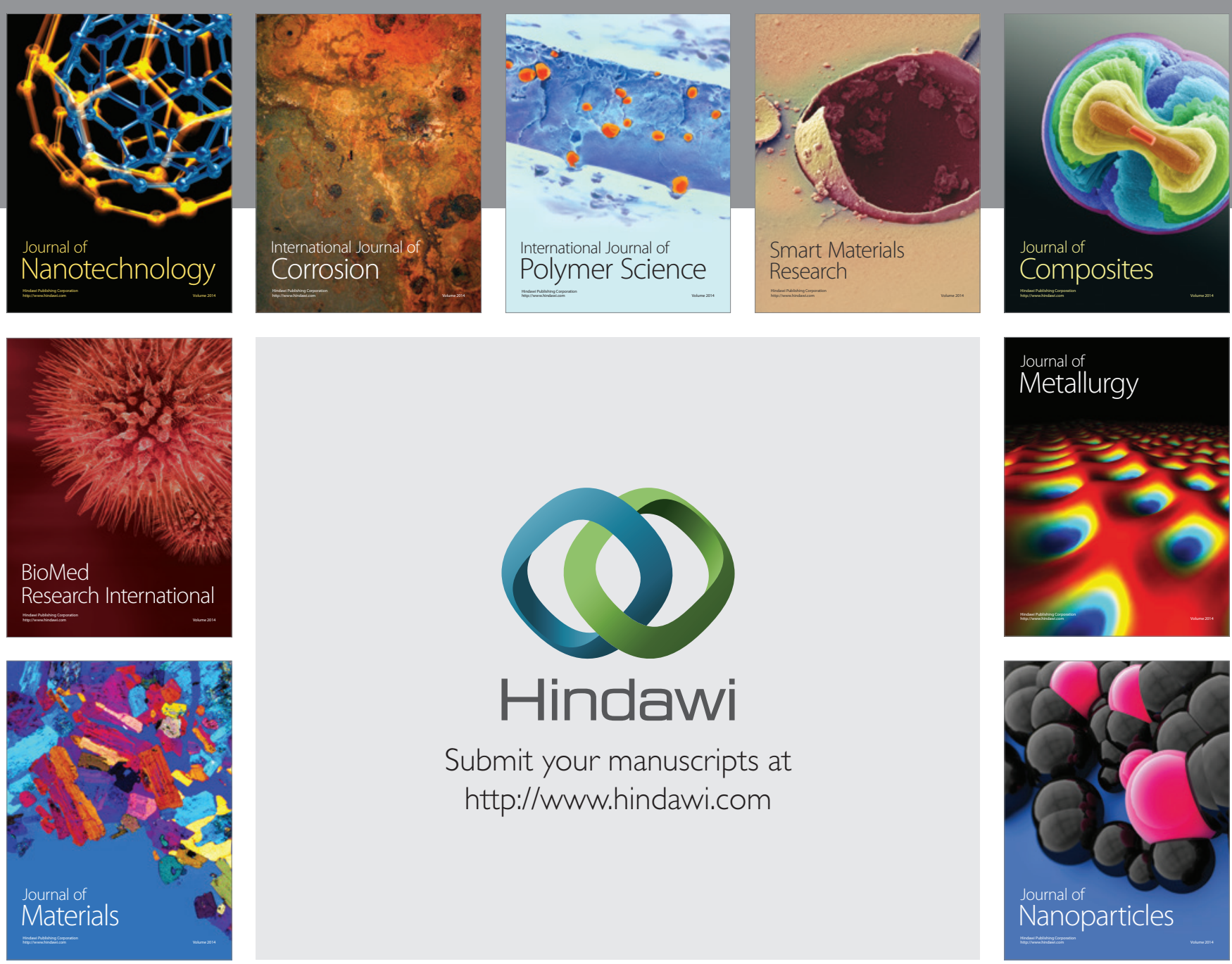

Submit your manuscripts at http://www.hindawi.com
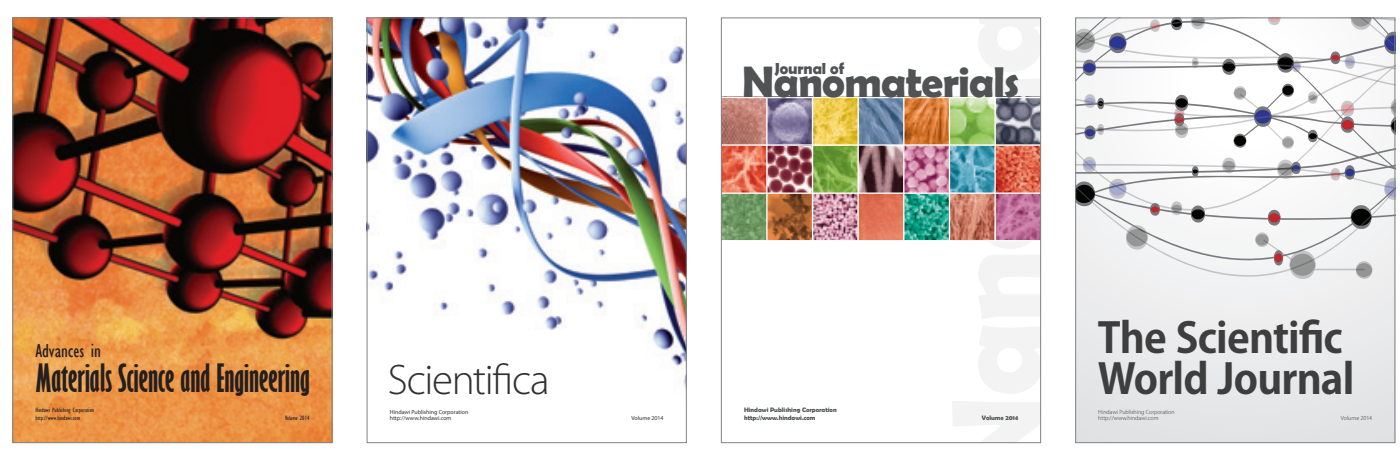

\section{The Scientific World Journal}
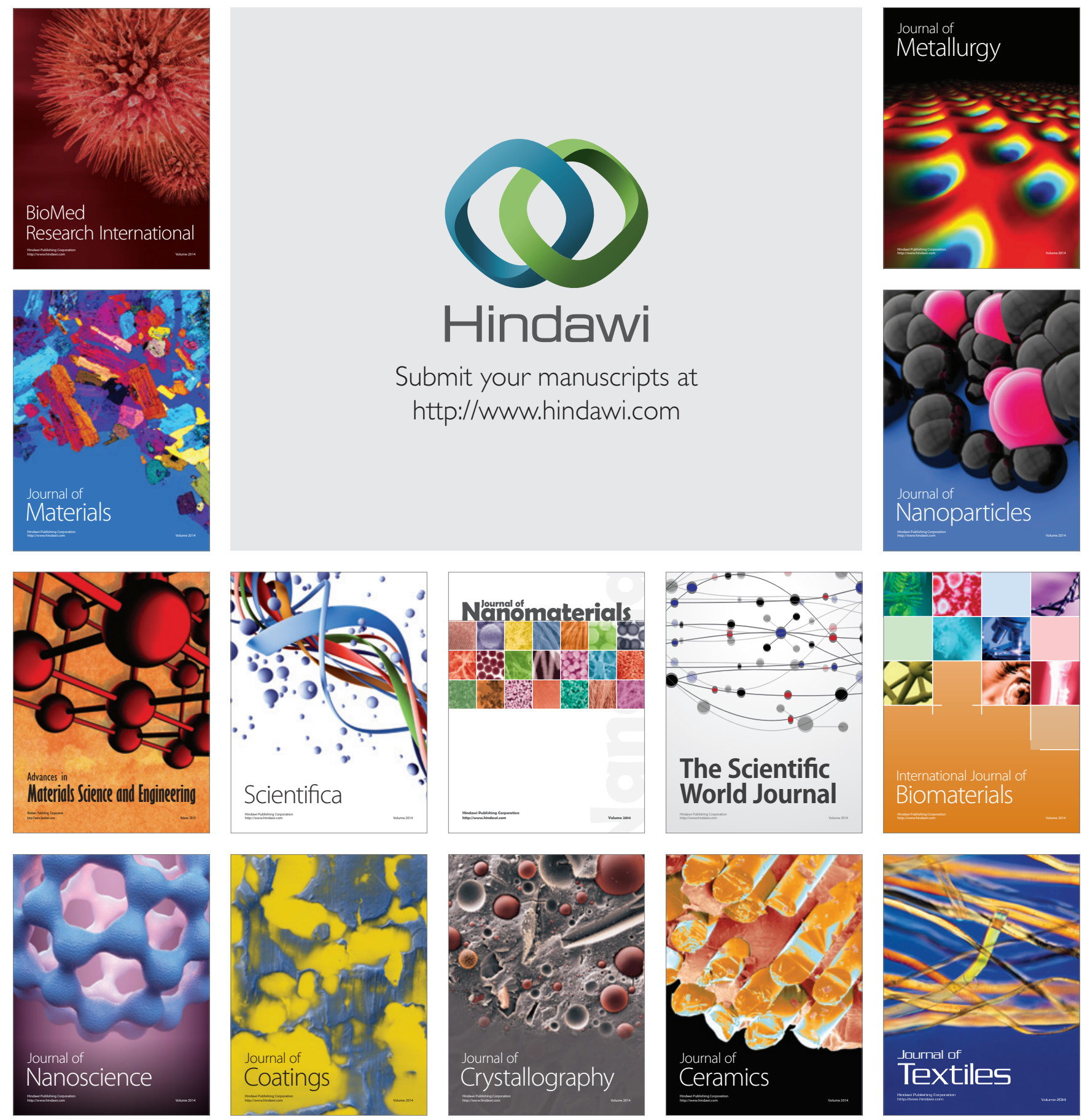